American Journal of Agricultural and Biological Sciences 6 (2): 209-213, 2011

ISSN 1557-4989

(C) 2011 Science Publications

\title{
Using Soil Plant Analysis Development Chlorophyll Meter for Two Growth Stages to Assess Grain Yield of Malaysian Rice (Oryza sativa)
}

\author{
${ }^{1}$ Asa Gholizadeh, ${ }^{1}$ Mohd Amin Mohd Soom, ${ }^{2}$ Anuar Abd. Rahim, ${ }^{3}$ Aimrun Wayayok \\ ${ }^{1}$ Department of Biology and Agricultural Engineering, Faculty of Engineering, \\ University Putra Malaysia, 43400, Serdang, Selangor, Malaysia \\ ${ }^{2}$ Department of Land Management, Faculty of Agriculture, University Putra Malaysia, \\ 43400, Serdang, Selangor, Malaysia \\ ${ }^{3}$ Smart Farming Technology Laboratory, Institute of Advanced Technology, \\ University Putra Malaysia, 43400, Serdang, Selangor, Malaysia
}

\begin{abstract}
Problem statement: Proper yield management in rice influences grain quality and quantity. Nitrogen site-specific management is also effective on final product of crops because excessive nitrogen application at any growth stage can reduce yield and increase disease incidence. In contrast, suboptimal nitrogen levels at discrete growth stages may substantially reduce plant productivity. The nitrogen status at specific growth stages may be used for estimating supplemental nitrogen requirements and yield potential. The SPAD chlorophyll meter is a quick and non-destructive tool used for directly measuring leaf chlorophyll and indirectly assessing the proportional parameter of leaf, plant nitrogen status and finally, grain yield. Approach: Describing within-field variability in a typical Malaysian paddy field was conducted to show the temporal variability of SPAD readings and also grain yield. Furthermore, the study aimed to introduce the rice growth stage which SPAD readings show higher relationship with grain yield. SPAD readings data was collected at two different growth stages (55 DAT and 80 DAT) using a Minolta SPAD 502. Grain yield was then collected at the end of the season to compare results with SPAD values. Results: Analysis of variance, variogram and kriging were conducted to determine the variability of parameters and also their relationship. Conclusion: Variability maps of the aforementioned parameters were generated. Increasing of SPAD values with growth stage could be observed in this study. SPAD readings taken at 55 DAT had a better relationship to grain yield than those taken at $80 \mathrm{DAT}$; therefore assessment of grain yield status is better to be done at 55 DAT.
\end{abstract}

Key words: Site-specific management, paddy field, temporal variability, spatial variability, Integrated Agricultural Development Area (IADA), chlorophyll meter, grain yield, Days After Transplanting (DAT), Statistical Package for Social Science (SPSS)

\section{INTRODUCTION}

Precision farming recently, has attracted interest and has seen some limited adoption in Asian countries. Reasons for this include social concern regarding environmental problems such as ecosystem damage and ground water pollution from the heavy use of agricultural chemicals that was seen as necessary to increase yields to feed rapid increasing populations on a limited amount of arable land, global demands for environmentally safe agriculture, pressure to strengthen the value of agricultural products to survive in competitive global markets and also labor shortage due to a decreasing and aging rural population. These factors are driving the change of agriculture to precision farming in Asia perhaps more than in North America, Europe and Australia.

Site-specific crop management can be described as a cyclical process of within field data collection, data analysis and optimum decision making, variable rate application and evaluation. Yield, crop growth status and soil properties are necessary data inputs to the system (Chung et al., 2001). Describing within-field variability in a typical Malaysian paddy is a fundamental first step toward determining the size of management zones and the inter-relationships between limiting factors, for the development of management strategies.

Corresponding Author: A. Gholizadeh, Department of Biology and Agricultural Engineering, Faculty of Engineering, University Putra Malaysia, 43400, Serdang, Selangor, Malaysia 
Based on SPAD meter readings being correlated with leaf N concentrations (Cen et al., 2006; Felix et al., 2002; Rostami et al., 2008; Yang et al., 2003), the meter provides a tool for the early detection of $\mathrm{N}$ deficiency in crops which is in high correlation to yield (Blackmer and Schepers, 1994). Rostami et al. (2008) also showed that there is a linear relationship between SPAD readings and grain yield that differed depending on plant developmental stage (Rostami et al., 2008). Relationships between leaf $\mathrm{N}$ content and photosynthetic capacity and between leaf chlorophyll and $\mathrm{N}$ and plant grain yield have also been demonstrated.

The main objectives of this study were to describe the temporal and spatial variability present in a typical paddy field, to determine that chlorophyll meter readings of flag leaf at which stage of rice growth shows higher value and to obtain the relationship between SPAD readings and grain yield in order to use it as a quick, cheap and effective mean in rice yield prediction.

\section{MATERIALS AND METHODS}

Study area: This study was conducted at the Tanjung Karang Rice Irrigation Scheme. The scheme area is located on a flat coastal plain in the Integrated Agricultural Development Area (IADA). It is in the district of Kuala Selangor and Sabak Bernam on latitude $3^{\circ} 35^{\prime \prime} \mathrm{N}$ and longitude $101^{\circ} 05^{\prime \prime} \mathrm{E}$. The scheme is composed of eight compartments which are divided into 24 blocks namely blocks A-X. The study area is in Block $\mathrm{C}$ which has 118 lots and each lot size is 1.2 ha with the total area of about 142 ha.

Crop measurement: Flag leaf samples were collected randomly in two different rice growth stages, at 55 Days After Transplanting (DAT) in March 2009 and also in April 2009 (80 DAT). The flag leaf of 20 plants in 60 lots was used for SPAD measurement. Triplicate readings were taken on one side of the midrib of each single leaf blade, midway between the leaf base and tip; all these readings then were averaged. Furthermore, at the end of season grain yield data was obtained in order to determine its relationship to SPAD readings at two different growth stages.

Conventional statistical and geostatistical analysis: The important information about variables is provided by descriptive statistics using the Statistical Package for Social Science (SPSS). Measures of central tendency of variables were determined by mean, median and mode as well as computing the dispersion of a variable in variance, standard deviation, coefficient of variation (CV) and range (Park, 2008). It should be noted that smaller values of $\mathrm{CV}$ represent lower variability and higher values of $\mathrm{CV}$ represent higher variability of data. Coefficient of Variation values of $<15 \%, 16-35 \%$ and $>36 \%$ indicate low, moderate and high variability of data distribution, respectively. Geostatistical analyses of SPAD readings were calculated for their semivariogram. A semivariogram indicates autocorrelation as a function of distance (semivariance versus distance separation) to plot spatial variability (Cohen et al., 1990). The components which include fitted model type, nugget variance $\left(\mathrm{C}_{0}\right)$, structural variance sill $\left(\mathrm{C}_{0}+\mathrm{C}\right)$, range $(\mathrm{A})$, residual sum of square (RSS), coefficient of determination $\left(\mathrm{R}^{2}\right)$ and proportion $\left(\mathrm{C} /\left[\mathrm{C}_{0}+\mathrm{C}\right]\right)$ were calculated by Geostatistics for the Environmental Science, Gamma Design Software. If the ratio of nugget to sill is less than or equal to $25 \%$, the variable is considered strongly spatially dependent, if the ratio is between 25 and $75 \%$, the variable is considered moderately spatially dependent and if the ratio is greater than $75 \%$, the variable is considered weakly spatially dependent (Cambardella and Karlen, 1999; Robertson, 2008).

Temporal and spatial variability maps: Variability has been identified as spatial, temporal and predictive. Temporal variability of SPAD readings at two different stages of plant growth (55 DAT and 80 DAT) and also grain yield were obtained in this study in order to evaluate their relationship. SPAD and yield data was interpolated geostatistically by kriging technique using ArcGIS software through spatial analyst extension based on semivariogram results derived from $\mathrm{GS}^{+}$software.

\section{RESULTS}

Relationship between SPAD readings for two growth stages and grain yield: Correlation of two stages SPAD readings and grain yield was analyzed by Pearson two-tail test to check the relationship of between them. The test showed that SPAD readings at 55 DAT had higher correlation coefficient with grain yield than 80 DAT.

Regression analysis of the data showed that grain yield was linearly correlated with the SPAD readings at both stages $\left(\mathrm{R}^{2}=0.81\right.$ and $\mathrm{R}^{2}=0.66$ for 55 DAT and 80 DAT, respectively) (Fig. 1-2). The linear regression of grain yield and SPAD values at both stages was significant at each growth stage $(\mathrm{P}<0.001)$. 


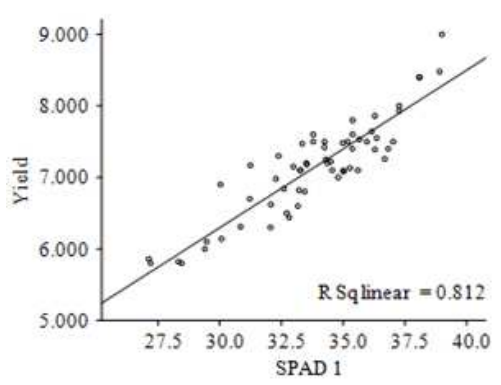

Fig. 1: Relationship between SPAD readings at 55 DAT and grain yield

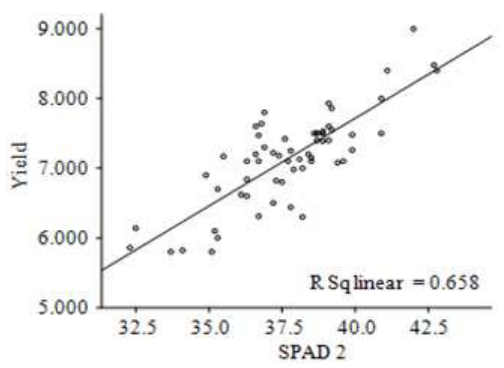

Fig. 2: Relationship between SPAD readings at 80 DAT and grain yield

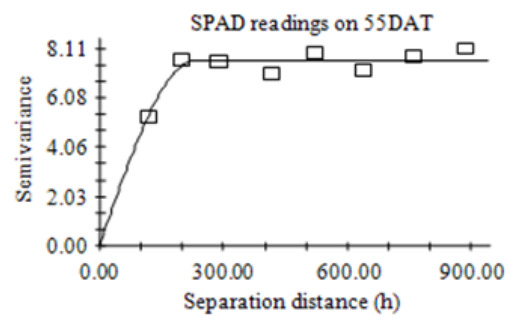

Fig. 3: Isotropic semivariogram of SPAD readings at 55 DAT

Geostatistical and semivariogram analysis: Geostatistical analyses of SPAD readings for two growth stages and grain yield were presented according to their semivariograms. As mentioned in the materials and methods, semivariogram had different variables and those are displayed in Table 1. Lag distance was set as $900 \mathrm{~m}$ with the lag interval of $120 \mathrm{~m}$.

Lag distance of each variogram were determined based on the width of the field. The nugget variance expressed as a percentage of the total semivariance was used to define distinct classes of spatial dependence for the soil variables. If the slope of the semivariogram was close to zero, regardless of the nugget ratio, the variable was considered to be randomly distributed. The variograms measured variables are shown in Fig. 3-5 respectively.

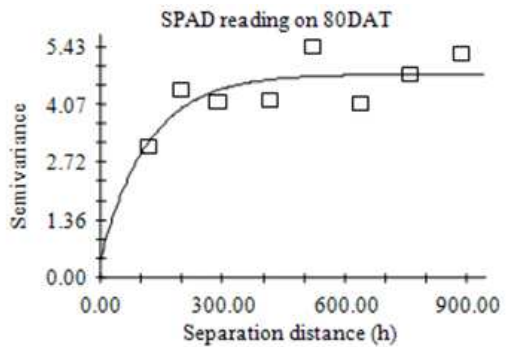

Fig. 4: Isotropic semivariogram of SPAD readings at 80 DAT

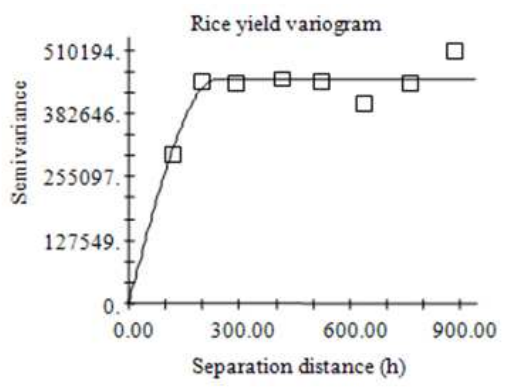

Fig. 5: Isotropic semivariogram of grain yield

Temporal and spatial variability maps: The classification approach using raster calculator, which was available in the spatial analyst for calculating the SPAD reading and calculated maps were produced. Since the standard classification did not show much variability for the SPAD readings and grain yield, smart quantile technique was selected to visualize variability. It was then decided to divide the area into 6 and 5 zones for SPAD readings and grain yield, respectively based on manageable zone which could be manageable and also easy to compare.

According to SPAD readings map at 55 DAT (Fig. 6), the areas were mostly occupied by the moderate range of 33.13-35.07 and it seemed to be concentrated in some lots in the south. The low SPAD readings (27.30-31.18) were scattered mostly in the center of the area while, the highest readings (35.0738.95) were observed in the northern lots.

The same pattern could be seen in the other map for SPAD readings at 80 DAT (Fig. 7) but the values were significantly higher than 55 DAT readings. It means that classes 1 and 2 (low values) in the 55 DAT map were not found in the 80 DAT map while classes 5 and 6 (high values) at 80 DAT map were not existed in the map of 55 DAT. Zonal statistics displayed that in 55 DAT map the area was covered by moderate values (31.18-35.07) for about 52\% of the total area. While 80 DAT map showed that $81 \%$ of the total area was covered by the higher SPAD readings of 35.07-38.95. 
Am. J. Agri. \& Biol. Sci., 6 (2): 209-213, 2011

Table 1: Summary of Isotropic semivariogram parameters

\begin{tabular}{llll} 
& SPAD $(55 \mathrm{DAT})$ & SPAD $(80 \mathrm{DAT})$ & Grain yield (ton/ha) \\
Model type & $-\mathrm{-o}$ & Spherical \\
\hline Nugget Variance $\left(\mathrm{C}_{\mathrm{o}}\right)$ & Spherical & Exponential & 1000 \\
Structural Variance Sill $\left(\mathrm{C}_{\mathrm{o}}+\mathrm{C}\right)$ & 0.05 & 0.41 & 450600 \\
Partial Sill & 7.62 & 4.77 & 449600 \\
Range $\left(\mathrm{A}_{\mathrm{o}}\right)$ & 7.57 & 4.36 & 239 \\
Residual Sum of Square $(\mathrm{RSS})$ & 231 & 354 & 6.25 \\
Coefficient $\left(\mathrm{R}^{2}\right)$ & 0.81 & 1.75 & 0.758 \\
Proportion $\left(\mathrm{C} /\left[\mathrm{C}_{\mathrm{o}}+\mathrm{C}\right]\right)$ & 0.85 & 0.56 & 0.998 \\
\hline
\end{tabular}

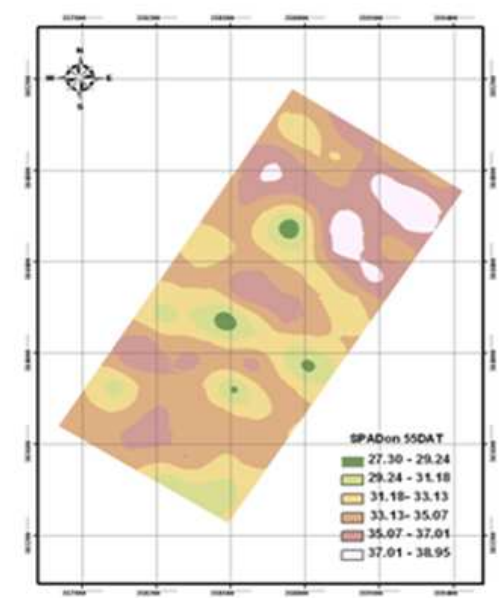

Fig. 6: Krigged map of SPAD readings at 55 DAT

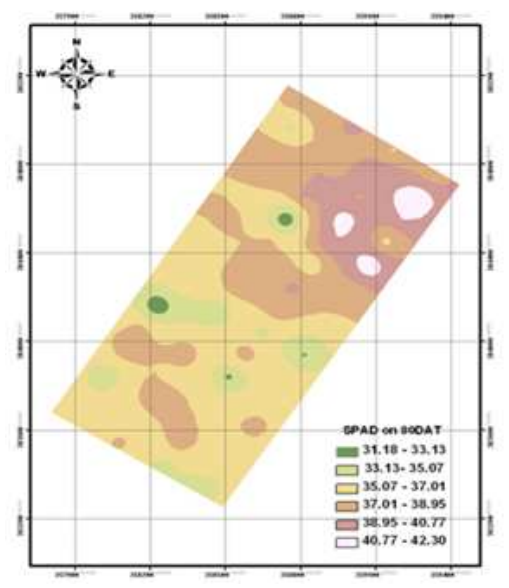

Fig. 7: Krigged map of SPAD readings at 80 DAT

The variability map grain yield (Fig. 8) illustrates that class $3(7080-7720 \mathrm{~kg}$ ) covered the largest area (more than $48 \%$ of the total area) and class 5 (the highest amount of grain yield) covered the smallest area.

Same pattern could be seen in all three maps above in terms of highest amount that they show (moderate class). It also showed that lots with high SPAD reading at two different growth stages displayed higher grain yield at the end of season.

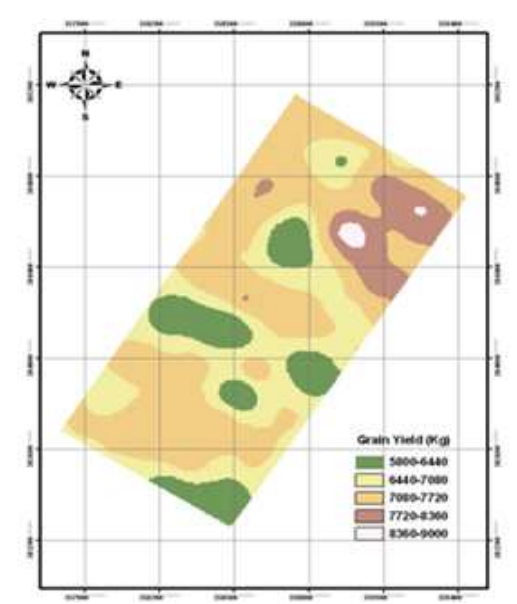

Fig. 8: Krigged map of grain yield classified by smart quantile method

\section{DISCUSSION}

Link between chlorophyll meter readings and crop yield which observed in this study also indicated by Rostami et al. (2008), Cartelat et al. (2005), LopezBellido et al. (2004), Costa et al. (2004) and Smeal and Zhang (1994) (Cartelat et al., 2005; Lopez-Bellido et al., 2004; Rostami et al., 2008). Moreover, Rostami et al. (2008) mentioned that the relationship between SPAD readings and grain yield in corn is not so high but this correlation positively rise at the second half of growth period $\left(\mathrm{R}^{2}=0.94\right)$ (Rostami et al., 2008). Varvel et al. (1997) also demonstrated high correlation between SPAD reading and grain yield (Varvel et al., 1997). Therefore, using SPAD chlorophyll meter could provide an indirect assessment of yield status based on this study and some other studies. Based on Gholizadeh et al. (2009) higher nugget on 80DAT indicates higher sampling error. Sill and the proportion of partial sill values were very weak or considered as pure nugget (Gholizadeh et al., 2009).

As mentioned in results the same pattern could be seen in both SPAD maps at 55 DAT and 80 DAT but the values were significantly higher at $80 \mathrm{DAT}$ readings 
which can be attributed to fertilizer application and other practices. This result is comparable to Rostami et al. (2008).

\section{CONCLUSION}

Higher SPAD values were obtained at $80 \mathrm{DAT}$, it means that different stages had different SPAD values and the change in the age of rice maturity was obviously different in terms of SPAD readings.

Higher correlation coefficient for the readings taken at 55 DAT; therefore assessment of crop yield status is better to be done at 55 DAT.

SPAD readings and yield maps were obtained using semivariograms analysis and point kriging which will be helpful for the development of digital farming and further analyzing of SPAD and yield. Visual observation and statistical analysis indicated the same trends could be observed in most areas of the field for aforementioned parameters.

Rice researchers using SPAD should use caution when transferring published relationships to other growth stages.

\section{ACKNOWLEDGEMENT}

This study has been financed by Universiti Putra Malaysia and Institute of Advanced Technology, it is appreciated. The authors also like to thank Institute of Advanced Technology staff for their help and support which highly improved this study.

\section{REFERENCES}

Blackmer, T.M. and J.S. Schepers, 1994. Techniques for monitoring crop nitrogen status in corn. Communi. Soil Sci. Plant Anal., 25: 1791-1800. DOI: 10.1080/00103629409369153

Cambardella, C.A. and D.L. Karlen, 1999. Spatial analysis of soil fertility parameters. Precision Agric., 1: 5-14. DOI: 10.1023/A:1009925919134

Cartelat, A., Z.G. Cerovic, Y. Goulas, S. Meyer and C. Lelarge et al., 2005. Optically assessed contents of leaf polyphenolics and chlorophyll as indicators of nitrogen deficiency in wheat (Triticum aestivum L.). Field Crops Research, 91: 35-49.

Cen, H., Y. Shao, H. Song and Y. He, 2006. Nondestructive estimation of rape nitrogen status using SPAD chlorophyll meter. Proceedings of the 8th International Conference on Signal Processing, Apr. 16-20, IEEE Xplore, Beijing, DOI: 10.1109/ICOSP.2006.344481
Chung, S.O., J.H. Sung, K.A. Sudduth, S.T. Drummond and B.K. Hyun. 2001. Spatial variability of yield, chlorophyll content and soil properties in a Korean rice paddy field. Proceedings of the 5th International Conference on precision agriculture, July 16-19, Bloomington, Minnesota, USA., pp: 1-4.

Cohen, W.B., T.A. Spies and G.A. Bradshaw, 1990. Semivariograms of digital imagery for analysis of conifer canopy structure. Remote Sens. Environ., 34: 167-178. DOI: 10.1016/0034-4257(90)90066-U

Felix, C.W.L., J.C. Grabosky and N.L. Bassuk, 2002. Using the SPAD 502 chlorophyll meter to assess chlorophyll and nitrogen content of Benjamin Fig and Cottonwood leaves. Horttechnology, 12: 682-686.

Gholizadeh, A., M.S.M. Amin, A.R. Anuar and W. Aimrun. 2009. Evaluation of leaf total nitrogen content for nitrogen management in a malaysian paddy field by using soil plant analysis development chlorophyll meter. Am. J. Agric. Biol. Sci., $\quad 4$ : 278-282. DOI: 10.3844/ajabssp.2009.278.282.

Lopez-Bellido, R.J, C.E. Shepherd and P.B. Barraclough, 2004. Predicting post-anthesis N requirements of bread wheat with a Minolta SPAD meter. Eurpean J. Agron., 20: 313-320. DOI: 10.1016/S1161-0301(03)00025-X

Park, H.M., 2008. Univariate analysis and normality test using SAS, Stata and SPSS. The Trustees of Indiana University. http://www.pcsglobe.com/elaa/statistics/normality. pdf

Robertson, G.P., 2008. GS+: Geostatistics for the environmental sciences. Gamma Design Software, Plainwell, Michigan, USA., http://www.gammadesign.com/files/GS+\%20User $\% 27$ s\%20Guide.pdf

Rostami, M., A. Koocheki, M.N. Mahallati and M. Kafi, 2008. Evaluation of chlorophyll meter (SPAD) data for prediction of nitrogen status in corn (Zea mays L.). Am.-Eurasian J. Agric. Environ. Sci., 3: 79-85.

Varvel, G.E., J S. Schepers and D.D. Francis, 1997. Ability for in-season correction of nitrogen deficiency in corn using chlorophyll meters. Soil Sci. Soc. Am. J., 61: 1233-1239.

Yang, W.H., S. Peng, J. Huang, A.L. Sanico, R.J. Buresh and C. Witt, 2003. Using leaf color charts to estimate leaf nitrogen status of rice. Agron. J., 95: 212-217. 